\title{
Machine Learning and Time Series Models for VNQ Market Predictions
}

\author{
Yu-Min Lian', Chia-Hsuan $\mathrm{Li}^{2}$ and Yi-Hsuan Wei ${ }^{3}$
}

\begin{abstract}
This study compares the price predictions of the Vanguard real estate exchangetraded fund (ETF) (VNQ) using the back propagation neural network (BPNN) and autoregressive integrated moving average (ARIMA) models. The input variables for BPNN include the past 3-day closing prices, daily trading volume, MA5, MA20, the S\&P 500 index, the United States (US) dollar index, volatility index, 5-year treasury yields, and 10-year treasury yields. In addition, variable reduction is based on multiple linear regression (MLR). Mean square error (MSE), mean absolute error (MAE), and mean absolute percentage error (MAPE) are used to measure the prediction error between the actual closing price and the models' forecasted price. The training set covers the period between January 1, 2015 and March 31, 2020, and the forecasting set covers the period from April 1, 2020 to June 30, 2020. The empirical results reveal that the BPNN model's predictive ability is superior to the ARIMA model's. The predictive accuracy of BPNN with one hidden layer is better than with two hidden layers. Our findings provide crucial market factors as input variables for BPNN that might inspire investors in VNQ markets.
\end{abstract}

JEL classification numbers: C32, C45, C53, G17.

Keywords: Vanguard real estate ETF (VNQ), Back propagation neural network (BPNN), Autoregressive integrated moving average (ARIMA), Multiple linear regression (MLR).

\footnotetext{
${ }^{1}$ Assistant Professor, Department of Business Administration, Fu Jen Catholic University, New Taipei City, Taiwan.

${ }^{2}$ Undergraduate Student, Department of Business Administration, Fu Jen Catholic University, New Taipei City, Taiwan.

${ }^{3}$ Undergraduate Student, Department of Business Administration, Fu Jen Catholic University, New Taipei City, Taiwan.
} 


\section{Introduction}

Real estate investment trusts (REITs) emerged in 1960 when the United States (US) Congress passed legislation permitting this new approach to real estate investment that broadened the channels through which well-capitalized investors could investdirectly through brokerages or indirectly through real estate stock. Since real estate could be securitized as a REIT that is listed and traded in a centralized market, investors without abundant assets could enjoy the profits enabled by centralized market trading, including property appreciation, higher market liquidity, a steady stream of rental income, portfolio diversification, and inflation protection.

After Box and Jenkins (1976) proposed ARIMA time series analysis, many researchers began a variety of studies.

Matyjaszek et al. (2019) used the autoregressive integrated moving average (ARIMA) model to predict Colombian coal prices, with the results of a mean absolute percentage error (MAPE) assessment of the ARIMA model being less than $0.2 \%$, indicating that the forecasted value was very close to the targeted price. Adebiyi et al. (2014) utilized ARIMA to predict the American and Nigerian stock indices and found that ARIMA was more suitable for short-term prediction. Lian and Liao (2015) applied the ICSS AR-GARCH models to analyze the volatility structure of oil futures market returns. The back propagation neural network (BPNN) is also used for prediction in many fields, and researchers have compared its predictive ability with other models. Hsieh et al. (2011) established that nonlinearity is a universal phenomenon in financial markets, so applying BPNN to predict stock prices is more effective. Grudnitski and Osburn (1993) adopted BPNN to predict price changes in an average month of gold futures and the S\&P 500; the results indicated that BPNN's accuracy rate for gold futures was $61 \%$ and for S\&P 500 was up to $75 \%$. Nazlioglu et al. (2020) performed research on the price and volatility interaction between the REITs of 19 countries and the crude oil market, and the results supported the significant influence of volatility. Ngo (2017) explored how variations in the US exchange rate impacted REIT returns. The results demonstrated that when US currency appreciated, REIT equity returns had the opposite variation. Chang (2017) investigated whether the REIT index could hedge against inflation risk; the results indicated that during a period of positive comovement, the REIT index could partially hedge against inflation.

Since linear or non-linear relationships may exist in financial data, the ARIMA model, a type of time series analysis that is not affected by exogenous variables, was used. In addition, BPNN was applied to analyze non-linear data and predict the VNQ price. Both models have been used to make precise predictions of various financial products. Therefore, the aim of this study is to investigate which model provides more valuable information to investors interested in REIT products. This study makes three major contributions. First, we model the behavior of VNQ prices by the BPNN and ARIMA models to understand the operation of the VNQ market. Our findings are valuable for the investment of other real estate-linked products for which the VNQ price dynamics are expected to follow the proposed models. Second, 
we apply the multiple linear regression (MLR) to conduct variable reduction and extract the statistically significant factors. Finally, we investigate the prediction performance of the BPNN and ARIMA models, compared with the actual VNQ data to conclude the best predictive model. The empirical results are significant for investors and for the organization of the VNQ market.

The remainder of this paper is organized as follows. Section 2 presents the principles of BPNN and the ARIMA model's methodology. Section 3 describes the empirical results. Section 4 concludes.

\section{Methodology}

\subsection{Back propagation neural network (BPNN)}

\subsubsection{Principle of neuron}

An artificial neural network (ANN) is composed of several input layers, one or more hidden layers, and an output layer. Each layer contains several homogeneous neurons, and includes a transfer function that calculates the output results from the input data, with weights representing the relationship importance and the data's correlation between each neuron. The formula for a neural network is as follows

$Y_{j}=($ net $)=f\left(\sum_{i=1}^{n} w_{i j} X_{i}-\theta_{j}\right)$

where $Y_{j}$ represents the target output, net represents the summation function, and $X_{i}$ is the input variables. The term $\mathrm{w}_{i j}$ is the weight of $j$ hidden layer neurons from $i$ input variables of the input layer. $\theta_{j}$ indicates the bias of the hidden layer neurons, and $f$ is the transfer function.

\subsubsection{Framework of BPNN}

BPNN is trained with supervised learning consisting of two steps-feed-forward and back propagation. In the feed-forward step, data are transferred from the hidden layer to the output layer. The network's predictive value is calculated using the gradient steepest descent method. When the predicted value differs from the result, the predictive value is subtracted from the target value to obtain a deviation, and then is back propagated to the network. In the back propagation step, the network adjusts the connected weights and predicts values close to the target value to minimize the loss function. Figure 1 shows the ANN framework. 


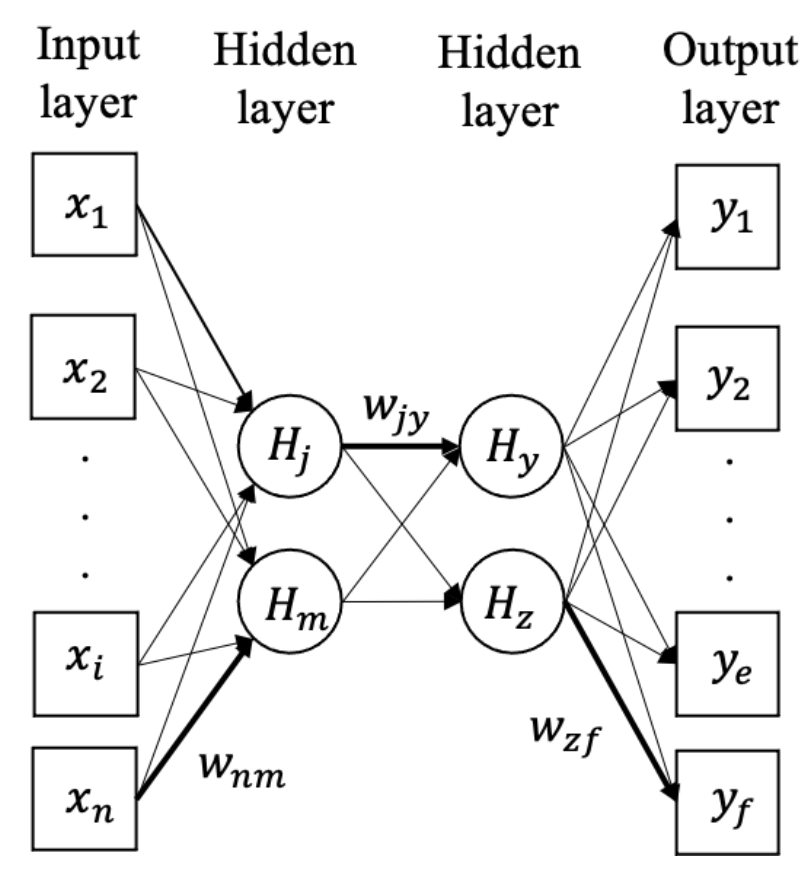

Figure 1: ANN Framework

\subsubsection{Transfer function}

The linear output of the former neuron can be transferred to non-linear output through the transfer function, which makes BPNN more capable of highly complex learning. The sigmoid function is widely used for the BPNN transfer function; its output value is between 0 and 1 and has continuous and differentiable characteristics. The sigmoid function is given by the following:

$(n e t)=\frac{1}{1+e x p^{-n e t}}$

\subsubsection{Parameter setting for BPNN}

The optimal number of hidden layers and neurons is determined by trial and error. The initial weights and thresholds are randomly produced by uniform distribution. The learning rate corrects the range of the weight adjustment when using the gradient steepest descent method. According to past experience, the learning rate is between 0.1 and 1.0, which creates a favorable convergence. To improve the vibration of the weight vectors or speed of convergence, neural networks usually utilize the momentum term to control the proportion of the weight variation. The value of the momentum term is between 0 and 1 . 


\subsection{ARIMA Model}

\subsubsection{Definition of ARIMA model}

There are three components of the ARIMA model autoregressive process (AR), integrated process (I), and moving average process (MA). By setting the order of $\operatorname{AR}(p)$, the degree of differencing $(d)$, and the order of $\operatorname{MA}(q)$, the $\operatorname{ARIMA}(p, d, q)$ model is constructed.

\section{Autoregressive process (AR)}

The AR model depends linearly on the previous terms, which indicates an autoregressive model of order $p$. The $\operatorname{AR}(p)$ model is defined as follows:

$y_{t}=a_{0}+\sum_{i=1}^{p} a_{i} y_{t-i}+\varepsilon_{t}$

where $a_{0}$ is the intercept of the constant term, $p$ is the order of lagged value, $a_{i}$ is the coefficient of $y_{t-i}$, and $\varepsilon_{t}$ is white noise.

II. Integrated process (I)

Before we conduct time series analysis, the input variables must be stationary. If we perform regression analysis with non-stationary variables, it may produce spurious regression results (Granger and Newbold, 1974). Most financial data are not completely stationary, but we can make them stationary with differencing. This is called an integrated process and denoted by $\mathrm{I}(d)$. The $\mathrm{I}(d)$ model can be expressed as follows:

$\Delta X_{t}=X_{t}-X_{t-1}$

where $\Delta X_{t}$ is first-order difference and $\Delta^{d} X_{t}$ indicates $d$-order differences.

III. Moving average process (MA)

The MA model has a similar structure to the AR model and is comprised linearly of past white noise terms, which is a linear regression model of order $q$. The $\operatorname{MA}(q)$ model can be written as follows:

$y_{t}=b_{0}+\sum_{i=1}^{q} b_{i} \varepsilon_{t-i}+\varepsilon_{t}$

where $b_{0}$ is the intercept of the constant term, $q$ is the order of lagged value, $b_{i}$ is the coefficient of $\varepsilon_{t-i}$, and $\varepsilon_{t}$ is white noise.

\subsubsection{Building the ARIMA model}

Time series data must be tested by unit root tests to ensure they are stationary. We applied three unit roots tests the Augmented Dickey-Fuller (ADF), Phillips-Perron (PP) and Kwiatkowski-Phillips-Schmidt-Shin (KPSS). If there are unit roots in time series $y_{t}$, this shows that $y_{t}$ has a stochastic trend, indicating that the data are nonstationary and must be processed with differencing. The next step is to decide the 
degree of differencing and transform the stochastic series into a stationary one. After the integration process, the subsequent step is the white noise test. Ljung-Box (LB) test is used and the null hypothesis is a random series, testing whether the variables of each term are autocorrelated. If no autocorrelation is indicated, then forecasting with the ARIMA model can proceed. The fourth step is to find the best value of $\operatorname{AR}(p)$ and $\operatorname{MA}(q)$. In this phase, it is popular to apply the autocorrelation function (ACF) and partial correlation function (PACF) and identify the lag orders of the ARIMA model with ACF and PACF plots. We use ACF and PACF plots to obtain order $q$ of MA and order $p$ of AR. ACF and PACF will converge to zero after a certain $q$ and $p$ number of lags, but when the lag orders of $\operatorname{AR}(p)$ and $\operatorname{MA}(q)$ are discontinuous or oscillating decay occurs, determining the best value of $p$ and $q$ by plots is not easy. Table 1 presents the criterion of identifying order $p$ of the AR process and order $q$ of the MA process with ACF and PACF plots.

Table 1: Features of ACF and PACF plots

\begin{tabular}{|c|c|c|}
\hline Model & ACF & PACF \\
\hline $\operatorname{AR}(p)$ & die-down & cut off after order $p$ \\
\hline $\operatorname{MA}(q)$ & cut off after order $q$ & die-down \\
\hline $\operatorname{ARMA}(p, q)$ & die-down & die-down \\
\hline
\end{tabular}

\subsubsection{Model selection}

When more than two models are selected during the ARIMA model-building process, we need to compare their goodness-of-fit and forecasting ability to determine the optimum model. Therefore, this study adopts the Akaike information criterion (AIC) and Schwartz Bayesian information criterion (BIC). The model with the minimum criteria value will be selected and viewed as exhibiting a better fit. This enables any misjudgment of the values of $p$ and $q$ using ACF and PACF plots to be avoided, as it is a more objective method.

\subsubsection{Performance assessment}

To evaluate and compare the performance of different models, forecasting key performance indicators (KPIs) -including MSE, mean absolute error (MAE), and MAPE- are applied. They all calculate the difference between the actual and predicted values. A lower estimator of MSE, MAE, and MAPE reflects better accuracy in model prediction.

\section{Empirical Analysis}

We apply BPNN and time series models to predict the VNQ price trend and evaluate prediction performance using MSE, MAE, and MAPE. The training set covers January 1, 2015-March 31, 2020, and the forecasting set covers April 1, 2020-June 
30, 2020. The data of BPNN and ARIMA models refer to trading information during the sample period provided by Yahoo! Finance.com.

\subsection{Back propagation neural network (BPNN)}

\subsubsection{Input variables}

Table 2 presents the 11 input variables selected for BPNN and their descriptions. MLR was used to conduct analysis, eliminating the input variables that exhibited non-significant correlations with the daily VNQ closing price.

Table 2: Selected input variables of the BPNN model

\begin{tabular}{|c|c|c|}
\hline \multicolumn{2}{|c|}{ Variables $\left(\boldsymbol{X}_{\boldsymbol{k}}\right)$} & Description \\
\hline$X_{1} \sim X_{3}$ & $P_{t-1} P_{t-2} P_{t-3}$ & Past three days closing price \\
\hline$X_{4} \sim X_{5}$ & $M A_{5} M A_{20}$ & 5 and 20 days moving average \\
\hline$X_{6}$ & $V o l$ & Daily trading volume \\
\hline$X_{7}$ & $D X Y$ & U.S. dollar index \\
\hline$X_{8}$ & $S \& P 500$ & S\&P 500 Index \\
\hline$X_{9}$ & $V I X$ & volatility index \\
\hline$X_{10}$ & $\wedge F V X$ & U.S. treasury yield 5 years \\
\hline$X_{11}$ & ${ }^{\wedge} T N X$ & U.S. treasury yield 10 years \\
\hline
\end{tabular}

Table 3 indicates that variables $X_{1}, X_{6}, X_{8}$ are statistically non-significant. Therefore, we retain variables $X_{2}, X_{3}, X_{4}, X_{5}, X_{7}, X_{9}, X_{10}, X_{11}$ to proceed with the follow-up analysis.

Table 3: Correlation tests between input variables using multiple linear regression analysis

\begin{tabular}{|c|c|c|c|}
\hline Variables $\left(\boldsymbol{X}_{\boldsymbol{k}}\right)$ & Coefficient & $\boldsymbol{t}$-value & $\boldsymbol{p}$-value \\
\hline Constant & $4.141^{*}$ & 4.542 & 0.000 \\
\hline$X_{1}$ & -0.031 & -1.042 & 0.298 \\
\hline$X_{2}$ & $-0.497^{*}$ & 15.926 & 0.000 \\
\hline$X_{3}$ & $-0.953^{*}$ & 31.609 & 0.000 \\
\hline$X_{4}$ & $2.502^{*}$ & 34.618 & 0.000 \\
\hline$X_{5}$ & $-0.078^{*}$ & -6.971 & 0.000 \\
\hline$X_{6}$ & $-3.8 \mathrm{E}-9$ & -0.378 & 0.705 \\
\hline$X_{7}$ & $0.022^{*}$ & 2.756 & 0.006 \\
\hline$X_{8}$ & 0.000 & 1.464 & 0.143 \\
\hline$X_{9}$ & $-0.046^{*}$ & -9.241 & 0.000 \\
\hline$X_{10}$ & $0.629^{*}$ & 2.442 & 0.015 \\
\hline$X_{11}$ & $-1.043^{*}$ & -3.574 & 0.000 \\
\hline
\end{tabular}

Notes: The model of multiple linear regression is denoted as $Y_{t}=\alpha+\sum_{i=1}^{11} \beta_{i} X_{i, t}+\varepsilon_{t}$, where $Y_{t}$ is VNQ series at time $t, X_{i, t}$ is the $i$ th input variable at time $t, \alpha$ is intercept, and $\varepsilon_{t} \sim \operatorname{iid}\left(0, \sigma^{2}\right)$. * represents under significance level of 0.05 is statistically significant. 


\subsubsection{Structure of BPNN}

With respect to parameters setting of BPNN, the training times is 2,000, sigmoid function is used as a transfer function, testing five learning rates: 0.1, 0.3, 0.5, 0.7, and 0.9 and three momentum factors: $0.5,0.7$, and 0.9 using the trial and error method to select the best parameters and predictive values for the BPNN models.

On the basis of an empirical rule, hidden layers are set within 1 2 of BPNN have the best convergence effect. Therefore, we used trial and error on 1 and 2 hidden layers. For the 1-hidden layer model, we set 1 14 hidden layer nodes; for the 2hidden layer model, 1 14 hidden layer nodes under the first hidden layer and 2 7 hidden layer nodes under the second hidden layer. Table 4 illustrates the parameter settings of hidden layers and hidden layer nodes.

Table 4: Parameter settings of hidden layers and hidden layer nodes

\begin{tabular}{|c|c|c|}
\hline & 1 hidden layer & 2 hidden layers \\
\hline Number of input nodes & 8 & 8 \\
\hline Number of 1st hidden layer nodes & $1 \sim 14$ & $1 \sim 14$ \\
\hline Number of 2nd hidden layer nodes & - & $2 \sim 7$ \\
\hline Number of output nodes & 1 & 1 \\
\hline
\end{tabular}

\subsubsection{Output variables}

The output variables for the BPNN model are the VNQ's closing stock prices.

\subsubsection{Performance assessment of BPNN}

We implement MSE, MAE, and MAPE as performance indicators to assess BPNN's forecasting ability. The lower the estimators yielded by MSE, MAE, and MAPE, the closer the predictive and actual prices are, which indicates a better goodness-offit for the BPNN we trained. Under the MSE, MAE, and MAPE criteria, Tables 57 indicate the top three BPNN models with one hidden layer; Tables 8-10 present the top three BPNN models with two hidden layers. BPNN with one hidden layer exhibits a lower predictive error than the 2-hidden layer model, indicating that the forecast ability of the 1-hidden layer BPNN model is better than that with two hidden layers.

Table 5: The top three 1-hidden layer BPNN models selected by MSE

\begin{tabular}{|c|c|c|c|c|c|}
\hline $\begin{array}{c}\text { MSE } \\
\text { ranking }\end{array}$ & $\begin{array}{c}\text { Number of } \\
\text { hidden layer }\end{array}$ & $\begin{array}{c}\text { Network } \\
\text { structure }\end{array}$ & $\begin{array}{c}\text { Learning } \\
\text { rate }\end{array}$ & $\begin{array}{c}\text { Momentum } \\
\text { term }\end{array}$ & MSE \\
\hline 1 & 1 & $08-04-01$ & 0.5 & 0.9 & 4.4069 \\
\hline 2 & 1 & $08-06-01$ & 0.7 & 0.7 & 4.7297 \\
\hline 3 & 1 & $08-04-01$ & 0.7 & 0.7 & 4.7358 \\
\hline
\end{tabular}


Table 6: The top three 1-hidden layer BPNN models selected by MAE

\begin{tabular}{|c|c|c|c|c|c|}
\hline $\begin{array}{c}\text { MAE } \\
\text { ranking }\end{array}$ & $\begin{array}{c}\text { Number of } \\
\text { hidden layer }\end{array}$ & $\begin{array}{c}\text { Network } \\
\text { structure }\end{array}$ & $\begin{array}{c}\text { Learning } \\
\text { rate }\end{array}$ & $\begin{array}{c}\text { Momentum } \\
\text { term }\end{array}$ & MAE \\
\hline 1 & 1 & $08-04-01$ & 0.5 & 0.9 & 1.8067 \\
\hline 2 & 1 & $08-04-01$ & 0.7 & 0.7 & 1.8727 \\
\hline 3 & 1 & $08-06-01$ & 0.7 & 0.7 & 1.8779 \\
\hline
\end{tabular}

Table 7: The top three 1-hidden layer BPNN models selected by MAPE

\begin{tabular}{|c|c|c|c|c|c|}
\hline $\begin{array}{c}\text { MAPE } \\
\text { ranking }\end{array}$ & $\begin{array}{c}\text { Number of } \\
\text { hidden layer }\end{array}$ & $\begin{array}{c}\text { Network } \\
\text { structure }\end{array}$ & $\begin{array}{c}\text { Learning } \\
\text { rate }\end{array}$ & $\begin{array}{c}\text { Momentum } \\
\text { term }\end{array}$ & MAPE \\
\hline 1 & 1 & $08-04-01$ & 0.5 & 0.9 & $149.4425 \%$ \\
\hline 2 & 1 & $08-04-01$ & 0.7 & 0.7 & $154.1757 \%$ \\
\hline 3 & 1 & $08-06-01$ & 0.7 & 0.7 & $154.8737 \%$ \\
\hline
\end{tabular}

Table 8: The top three 2-hidden layer BPNN models selected by MSE

\begin{tabular}{|c|c|c|c|c|c|}
\hline $\begin{array}{c}\text { MSE } \\
\text { ranking }\end{array}$ & $\begin{array}{c}\text { Number of } \\
\text { hidden } \\
\text { layer }\end{array}$ & $\begin{array}{c}\text { Network } \\
\text { structure }\end{array}$ & $\begin{array}{c}\text { Learning } \\
\text { rate }\end{array}$ & $\begin{array}{c}\text { Momentum } \\
\text { term }\end{array}$ & MSE \\
\hline 1 & 2 & $08-02-05-01$ & 0.5 & 0.7 & 5.6697 \\
\hline 2 & 2 & $08-02-05-01$ & 0.1 & 0.5 & 6.7916 \\
\hline 3 & 2 & $08-07-03-01$ & 0.7 & 0.9 & 6.8971 \\
\hline
\end{tabular}

Table 9: The top three 2-hidden layer BPNN models selected by MAE

\begin{tabular}{|c|c|c|c|c|c|}
\hline $\begin{array}{c}\text { MAE } \\
\text { ranking }\end{array}$ & $\begin{array}{c}\text { Number of } \\
\text { hidden } \\
\text { layer }\end{array}$ & $\begin{array}{c}\text { Network } \\
\text { structure }\end{array}$ & $\begin{array}{c}\text { Learning } \\
\text { rate }\end{array}$ & $\begin{array}{c}\text { Momentum } \\
\text { term }\end{array}$ & MAE \\
\hline 1 & 2 & $08-02-05-01$ & 0.5 & 0.7 & 1.8928 \\
\hline 2 & 2 & $08-02-05-01$ & 0.1 & 0.5 & 2.1985 \\
\hline 3 & 2 & $08-02-04-01$ & 0.1 & 0.7 & 2.2294 \\
\hline
\end{tabular}


Table 10: The top three 2-hidden layer BPNN models selected by MAPE

\begin{tabular}{|c|c|c|c|c|c|}
\hline $\begin{array}{c}\text { MAPE } \\
\text { ranking }\end{array}$ & $\begin{array}{c}\text { Number } \\
\text { of hidden } \\
\text { layer }\end{array}$ & $\begin{array}{c}\text { Network } \\
\text { structure }\end{array}$ & $\begin{array}{c}\text { Learning } \\
\text { rate }\end{array}$ & $\begin{array}{c}\text { Momentum } \\
\text { term }\end{array}$ & MAPE \\
\hline 1 & 2 & $08-02-05-01$ & 0.5 & 0.7 & $158.0688 \%$ \\
\hline 2 & 2 & $08-02-05-01$ & 0.1 & 0.5 & $181.2002 \%$ \\
\hline 3 & 2 & $08-02-04-01$ & 0.1 & 0.7 & $183.6018 \%$ \\
\hline
\end{tabular}

Figures 2 and 3 present run charts of 1- and 2-hidden layer BPNN models during the training period. We select the BPNN model with the best predictive power; the network structure with one hidden layer is (08-04-01), with a learning rate of 0.5 and a momentum factor of 0.9 . As for BPNN with two hidden layers, the best structure is (08-02-05-01), with a learning rate of 0.5 and a momentum factor of 0.7. Overall, both the 1- and 2-hidden layer BPNN models' goodness-of-fit are excellent during the training period.

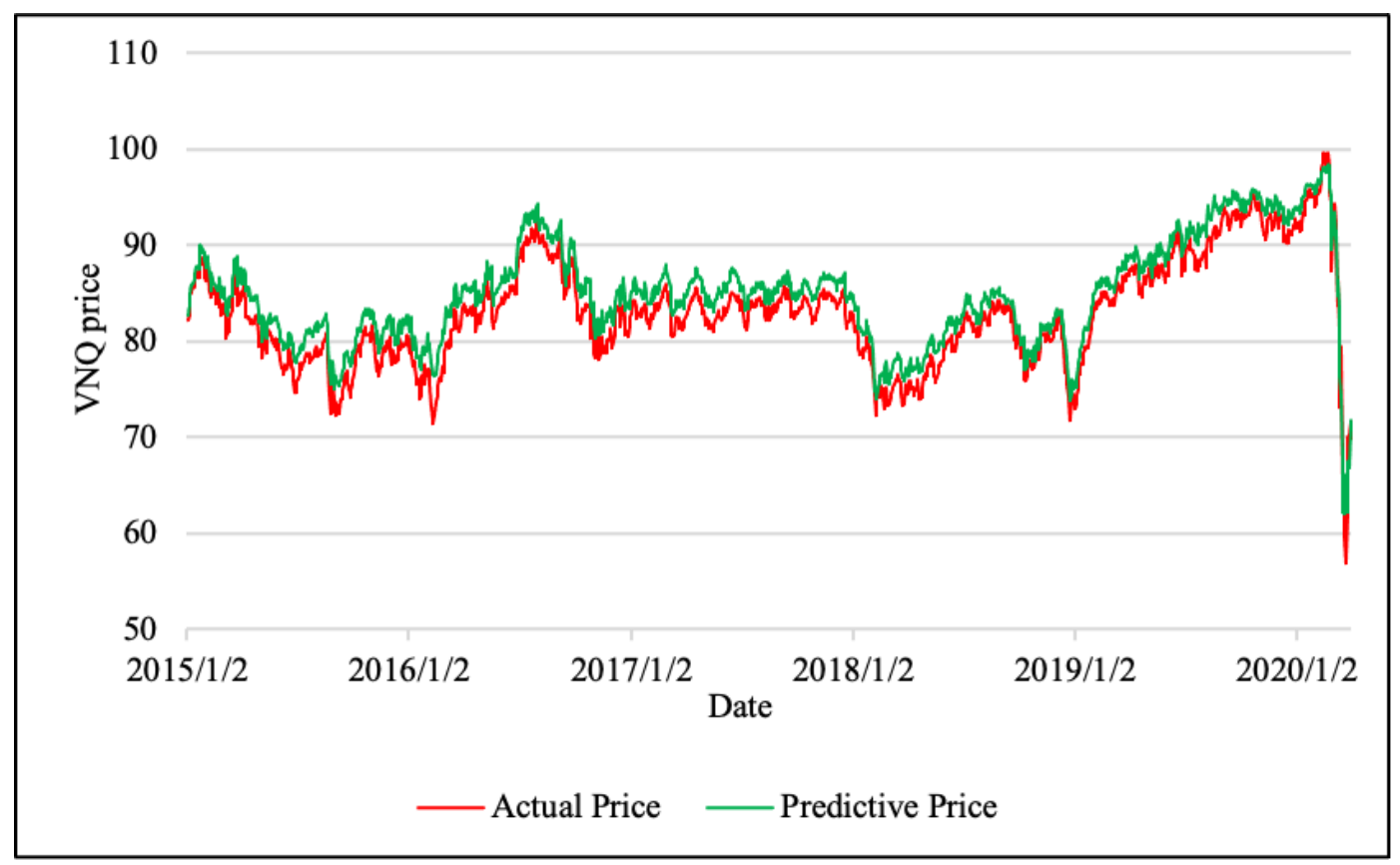

Figure 2: Training period of the best 1-layer BPNN model 


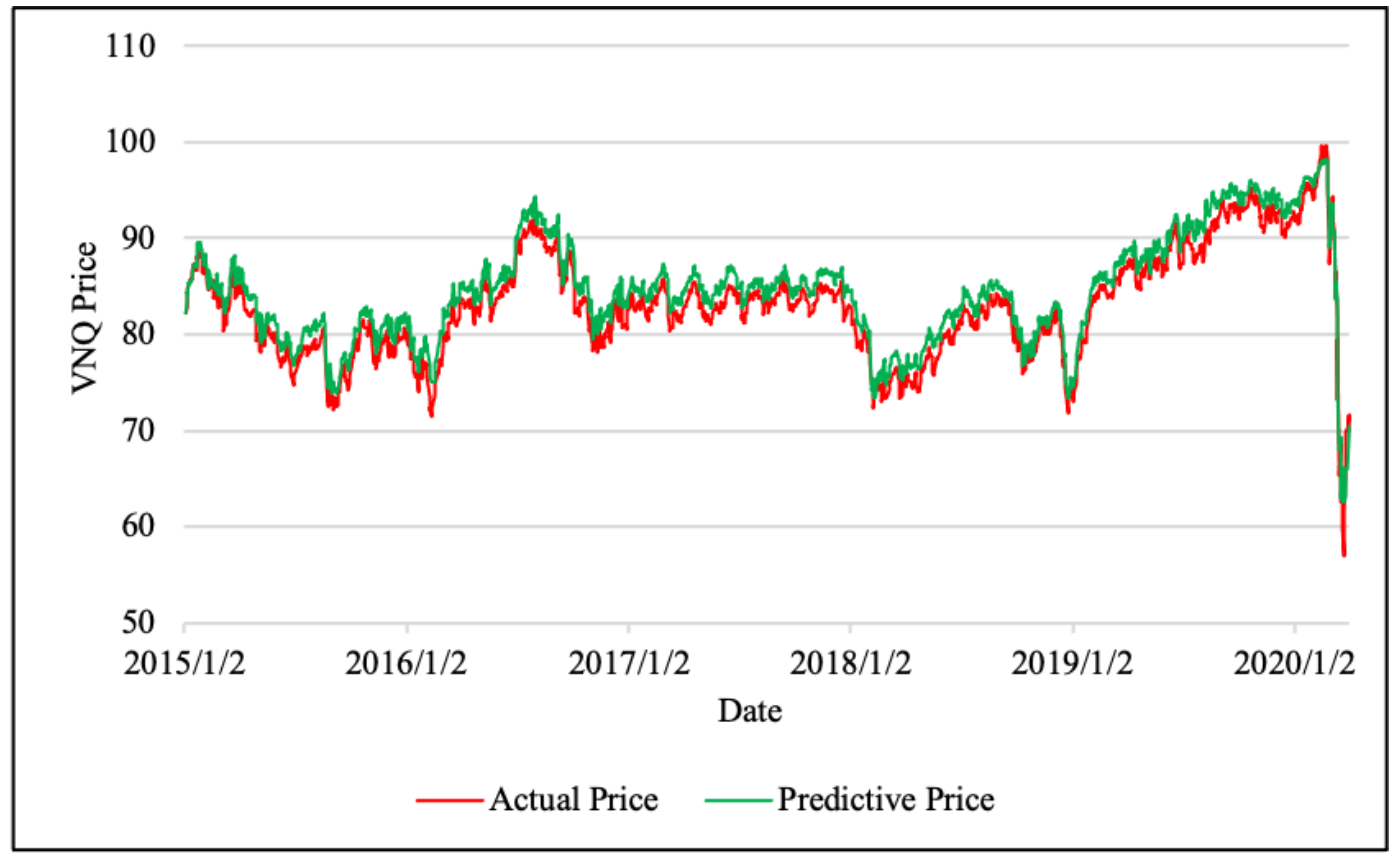

Figure 3: Training period of the best 2-layers BPNN model.

\subsection{Estimated results from the ARIMA model}

\subsubsection{Unit root tests}

ADF, PP, and KPSS were used to test if the data series was stationary. The initial data series was not stationary and could not be used. After first-order differencing, the data series appeared stationary. Table 11 demonstrates the unit root test results.

Table 11: ADF, PP, KPSS tests on the VNQ price (2015/01/01-2020/03/31)

\begin{tabular}{|c|c|c|c|}
\hline & ADF & PP & KPSS \\
\hline Level & $-3.714(10)$ & $-3.817(10)$ & $9.822(0)^{*}$ \\
\hline $1^{\text {st }}$ difference & $-12.046(9)^{*}$ & $-40.865(0)^{*}$ & $0.027(1)$ \\
\hline
\end{tabular}

Notes: * represents statistical significance at 0.05 level.

\subsubsection{LB test}

According to Table 12, the $p$-value is less than the 0.05 confidence level. As a result, the $\mathrm{I}(1)$ series meets the autocorrelation condition for time series analysis.

Table 12: White noise test on the VNQ price of first-order difference (2015/01/01-2020/03/31)

\begin{tabular}{|c|c|}
\hline & $p$-value \\
\hline $1^{\text {st }}$ difference of series & $7.7763 \mathrm{e}-22$ \\
\hline
\end{tabular}




\subsubsection{PACF and ACF}

We use PACF and ACF to determine the $p$ and $q$ orders of ARIMA. According to Figure 4, most of the lags exceeding the confidence interval are between 1 and 10 , so we construct $\operatorname{ARIMA}(0,1,1), \operatorname{ARIMA}(0,1,2)$, and $\operatorname{ARIMA}(10,1,10)$ models, and so on, to evaluate model fitness.
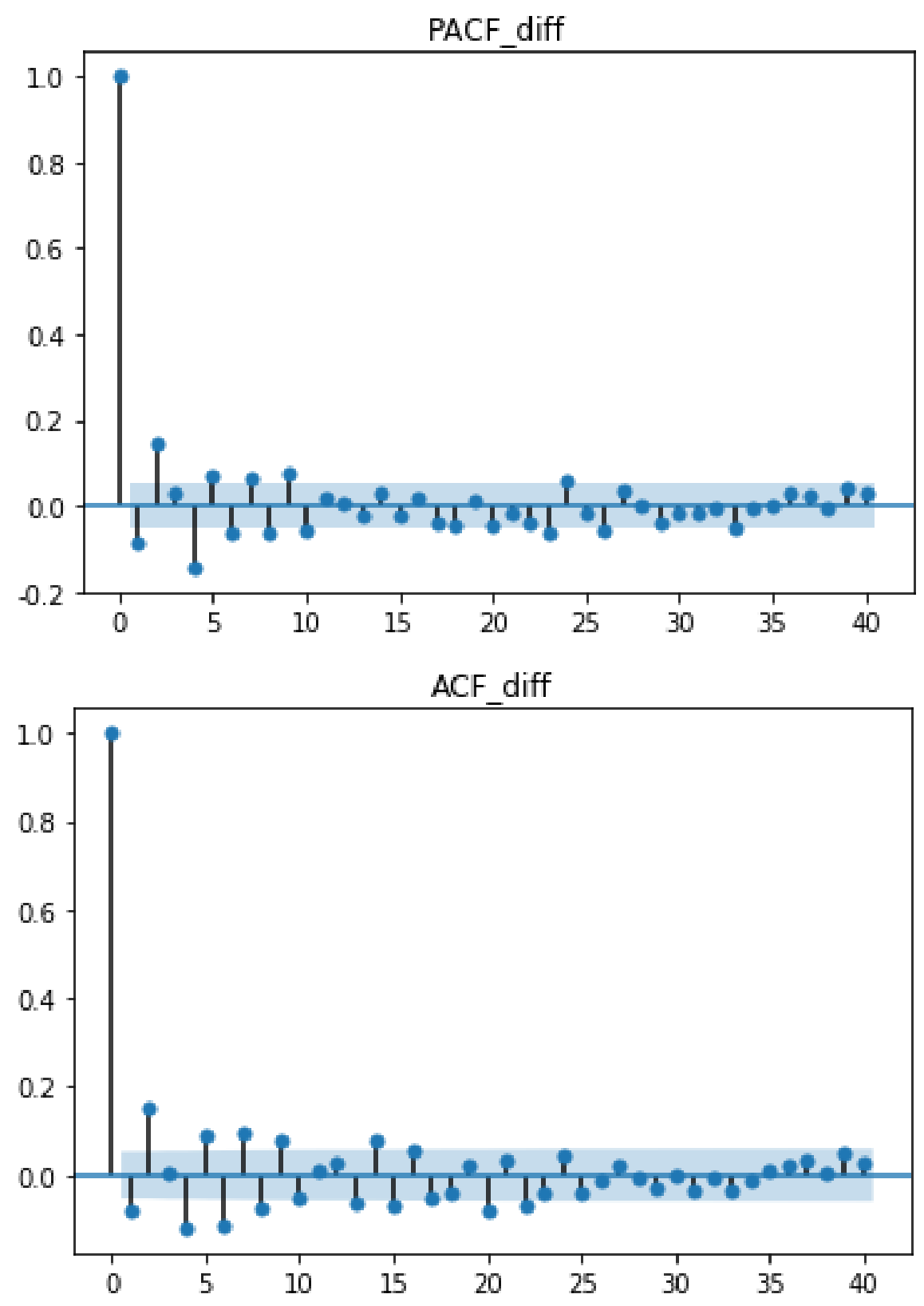

Figure 4: PACF and ACF of the $1^{\text {st }}$ differenced VNQ price 


\subsubsection{AIC and BIC}

Since there are many ARIMA models selected by ACF and PACF, AIC and BIC were used to test the goodness-of-fit and determine the better prediction models. Based on Table 13, the models within the top four ranks of AIC and BIC were selected and their prediction performance was compared.

Table 13: AIC and BIC tests on the VNQ price (2015/01/01-2020/03/31)

\begin{tabular}{|c|c|c|c|c|c|}
\hline Ranking & ARIMA & AIC & Ranking & ARIMA & BIC \\
\hline 1 & ARIMA(10,1,7) & 4042.83 & 1 & ARIMA $(4,1,1)$ & 4104.04 \\
\hline 2 & ARIMA(10,1,9) & 4043.68 & 2 & ARIMA(3,1,2) & 4105.87 \\
\hline 3 & ARIMA(10,1,4) & 4048.82 & 3 & ARIMA $(2,1,3)$ & 4107.22 \\
\hline 4 & ARIMA(9,1,4) & 4049.30 & 4 & ARMIA(5,1,2) & 4108.06 \\
\hline
\end{tabular}

\subsubsection{Performance}

Finally, we compare the prediction deviation with MSE, MAE, and MAPE. Table 14 presents the prediction assessment of the ARIMA model. According to the white noise test for the standardized residuals of $\operatorname{ARIMA}(5,1,2)$, the result shows that the $p$-value is 0.2082 , representing that the standardized residuals of the series are white noise.

Table 14: Prediction assessment on the ARIMA model (2020/04/01-2020/06/30)

\begin{tabular}{|c|c|c|c|c|}
\hline Ranking & Model & MSE & MAE & MAPE \\
\hline 1 & ARIMA(5,1,2) & 13.4917 & 2.9729 & $245.3333 \%$ \\
\hline 2 & ARIMA(10,1,7) & 13.8485 & 3.0188 & $248.5046 \%$ \\
\hline 3 & ARIMA(3,1,2) & 60.5569 & 6.5750 & $520.9969 \%$ \\
\hline 4 & ARIMA $(4,1,1)$ & 60.8947 & 6.5964 & $522.6878 \%$ \\
\hline 5 & ARIMA $(9,1,4)$ & 65.7327 & 6.8753 & $544.9113 \%$ \\
\hline 6 & ARIMA(10,1,4) & 70.4106 & 7.1698 & $568.6037 \%$ \\
\hline
\end{tabular}

\subsection{Comparison}

Table 15 demonstrates the prediction errors of the best with 1- and 2-hidden layer BPNN models and the ARIMA model. Whether with MSE, MAE, or MAPE, BPNN exhibits a smaller loss function than ARIMA, which reveals that BPNN is more accurate. With either one or two hidden layers, the trend in the predicted VNQ price is similar to the actual value. 
Table 15: Comprehensive performance assessment

\begin{tabular}{|c|c|c|c|}
\hline MSE ranking & $\mathbf{1}$ & $\mathbf{2}$ & $\mathbf{3}$ \\
\hline Model & BPNN(8-4-1) & BPNN(8-2-5-1) & ARIMA(5,1,2) \\
\hline MSE & 4.4069 & 5.6697 & 13.4917 \\
\hline MAE ranking & $\mathbf{1}$ & $\mathbf{2}$ & $\mathbf{3}$ \\
\hline Model & BPNN(8-4-1) & BPNN(8-2-5-1) & ARIMA(5,1,2) \\
\hline MAE & 1.8067 & 1.8928 & 2.9729 \\
\hline MAPE ranking & $\mathbf{1}$ & $\mathbf{2}$ & $\mathbf{3}$ \\
\hline Model & BPNN $(8-4-1)$ & BPNN(8-2-5-1) & ARIMA $(5,1,2)$ \\
\hline MAPE & $149.4425 \%$ & $158.0688 \%$ & $245.3333 \%$ \\
\hline
\end{tabular}

As depicted in Figure 5, the ARIMA model is a linear data-generating process, so its predictive line exhibits a steady and slowly rising trend. The empirical analysis demonstrates that BPNN shows better forecasting performance.

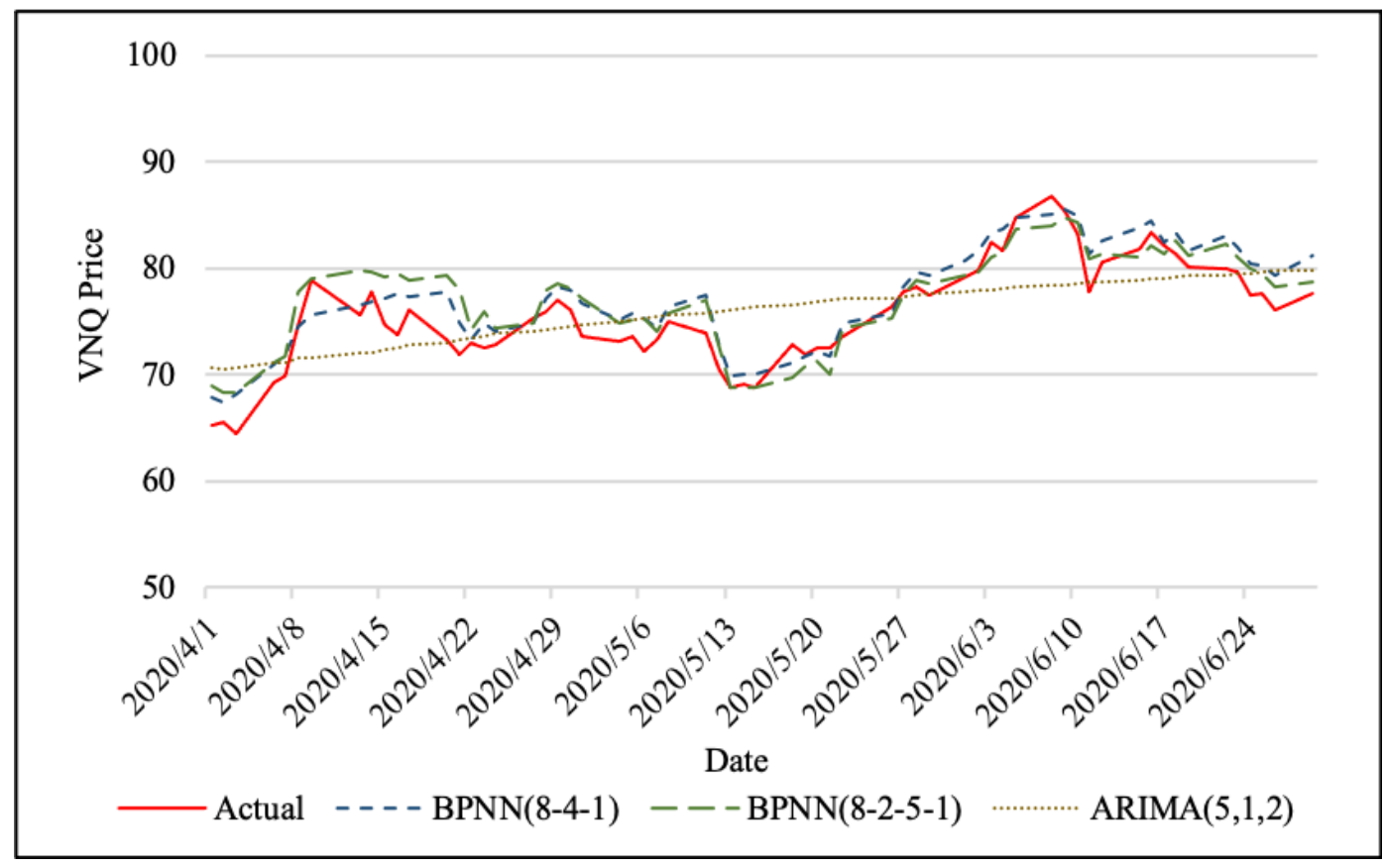

Figure 5: Forecast price and actual price trends during the testing period

\section{Conclusions}

Python was used to program BPNN and ARIMA to construct price forecasting models for VNQ. With BPNN, the transfer function was the sigmoid function and the input variable selection was done with MLR analysis to reinforce the predictive power of the network structure, from which the past 1-day closing price, daily 
trading volume, and S\&P 500 were eliminated. Conversely, the input variables are statically significant at a $5 \%$ significance level and, as follows, $P_{t-2}, P_{t-3}, M A 5$, $M A 20, D X Y, V I X,{ }^{\wedge} F V X$, and ${ }^{\wedge} T N X$ (refer to Table 2). According to the empirical results, the best BPNN structure is with one hidden layer, four hidden layer nodes, a learning rate of 0.5 , and a momentum factor of 0.9. In the ARIMA model, AIC and BIC were utilized to obtain the top four ARIMA models with the best goodnessof-fit. MSE, MAE, and MAPE were used to comprehensively compare errors, and the best ARIMA $(5,1,2)$ model was tested for white noise. Since the null hypothesis could not be rejected, it indicates that ARIMA $(5,1,2)$ had fully collected data from the sequences and exhibited a good fit. Finally, comparing the forecasting ability of BPNN and ARIMA using three performance assessment indicators, BPNN's predictive errors are significantly lower than those of ARIMA. BPNN outperforms the ARIMA time series model in predicting the VNQ market price. Referring to forecasting run charts, the VNQ price trend predicted by BPNN is also closer to the actual price. This study's results provide influential market factors with higher VNQ price correlations and a superior forecasting model, representing practical advice and references for those considering VNQ market investments.

\section{Acknowledgments}

Yu-Min Lian is grateful to the Ministry of Science and Technology (MOST) for support through Project No.: MOST109-2410-H-030-019-MY2. 


\section{References}

[1] Adebiyi, A.A., Adewumi, O.A. and Ayo, K.C. (2014). Stock price prediction using the ARIMA model. UKSim-AMSS 16th International Conference on Computer Modelling and Simulation, pp. 106 - 112.

[2] Box, G.E.P. and Jenkins, G.M. (1976). Time series analysis forecasting and control. Holden-Day, San Francisco.

[3] Chang, K.L. (2017). Does REIT index hedge inflation risk? New evidence from the tail quantile dependences of the Markov-switching GRG copula. North American Journal of Economics and Finance, 39, pp. 56 - 67.

[4] Granger, C.W.J. and Newbold, P. (1974). Spurious regressions in econometrics. Journal of Econometrics, 2, pp. 111 - 120.

[5] Grudnitski, G. and Osburn, L. (1993). Forecasting S\&P and gold futures prices: An application of neural networks. Journal of Futures Markets, 3, pp. 631 643.

[6] Hsieh, L.F., Hsieh, S.C. and Tai, P.H. (2011). Enhanced stock price variation prediction via DOE and BPNN-based optimization. Expert Systems with Applications, 38, pp. 14178 - 14184.

[7] Lian, Y.M. and Liao, S.Z. (2015). The volatility structure of oil futures market returns: An empirical investigation. Investment Management and Financial Innovations, 12, pp. 16 - 25.

[8] Matyjaszek, M., Fernández, R.P., Krzemień, A., Wodarski, K. and Valverde, F.G. (2019). Forecasting coking coal prices by means of ARIMA models and neural networks, considering the transgenic time series theory. Resources Policy, 61, pp. 283 - 292.

[9] Nazlioglu, S., Gupta, R., Gormus, A. and Soytas, U. (2020). Price and volatility linkages between international REITs and oil markets. Energy Economics, 88, Article. 104779.

[10] Ngo, T. (2017). Exchange rate exposure of REITs. Quarterly Review of Economics and Finance, 68, pp. 249 - 258. 